\title{
Um sistema automático de baixo custo para medidas de intervalos de tempo
}

\author{
A low-cost automatic system to measure time intervals
}

\author{
Fabio F. Luiz ${ }^{1}$, Luiz Eduardo S. Souza ${ }^{2}$, Paulo H. Domingues*3 \\ ${ }^{1}$ Centro Universitário Moacyr Sreder Bastos, Rio de Janeiro, RJ, Brasil \\ ${ }^{2}$ Escola de Ciências, Educação, Letras, Artes e Humanidades, Universidade do Grande Rio, \\ Duque de Caxias, RJ, Brasil \\ ${ }^{3}$ Instituto de Física, Universidade Federal do Rio de Janeiro, Rio de Janeiro, RJ, Brasil
}

Recebido em 7 de julho de 2015. Aceito em 5 de dezembro de 2015

\begin{abstract}
São descritos a construção e o funcionamento de um sistema de aquisição de dados automático de muito baixo custo formado por uma chave óptica (photogate) ativada por luz infravermelha, do tipo convencional, e um cronômetro digital comum com 0,01 s de resolução, alterado para ser acionado e parado eletronicamente pela chave óptica. O sistema é projetado para uso em medidas de intervalos de tempo e pode ser utilizado tanto em laboratórios universitários de física experimental como nos de Ensino Médio de física.
\end{abstract}

Palavras-chave: chave óptica, cronômetro, material de baixo custo, medidas de tempos.

It is described a very low cost system for automatic data acquisition consisting of a conventional photogate activated by infrared light, and a digital stopwatch with $0,01 \mathrm{~s}$ of resolution with the start/stop functions triggered by the photogate. The system is designed to determine time intervals and is intended for use in both first year undergraduate physics courses and in high school experimental physics laboratories.

Keywords: photogate, stopwatch, low-cost materials, time interval measurements.

\section{Introdução}

O objetivo básico da construção de equipamentos de baixo custo para laboratórios de ensino é sua utilização em qualquer laboratório de física, tanto universitário como do ensino básico, e em lugares onde a carência de recursos, tanto humanos como materiais, é um fator limitante das atividades laboratoriais de ensino. Portanto, uma das caraterísticas essenciais desses equipamentos deve ser em primeiro lugar, além da acurácia das medidas, o baixo custo dos materiais e a facilidade de encontrá-los nos mercados locais; em segundo lugar, para a sua construção, em geral, é necessário uma habilidade manual mediana e/ou algum conhecimento básico de eletrônica, principalmente quando se lida com equipamentos para medidas automáticas de tempo, como é o presente caso. Dito em outras palavras, equipamento de baixo-custo não significa apenas o baixo custo dos

*Endereço de correspondência: paulodom@if.ufrj.br materiais empregados (quase todos os materiais empregados na construção de equipamentos de ensino básico custam pouco!). Aos equipamentos ditos de baixo-custo deve ser agregado, também, a mão-deobra especializada e o conhecimento técnico sobre o assunto. Assim, para que um equipamento possa ser considerado de baixo custo para uso em ensino de física, seja em nível superior como no ensino básico, é necessário também uma complexidade mínima para a execução do projeto. Qualquer técnico de nível médio, e em qualquer lugar, deve ser capaz de executá-lo a partir dos esquemas publicados

Um dos assuntos mais estudados nos cursos de física experimental refere-se à medição de intervalos de tempo quando analisamos o movimento de corpos: a determinação do período de um movimento harmônico simples e o intervalo de tempo gasto para percorrer a distância entre dois pontos. Esses tempos são determinados, no mais das vezes, com o auxílio de um cronômetro digital manual. $\mathrm{O}$ 
problema dessa técnica vem da dificuldade de determinarmos corretamente os intervalos de tempo com o uso de cronômetros digitais encontrados comercialmente, devido ao fato que esses cronômetros possuem resolução de um centésimo do segundo enquanto que o nosso tempo de resposta, tanto na partida como na parada do cronômetro, é na melhor das hipóteses, da ordem do décimo de segundo.

Várias alternativas tem sido propostas para resolver esse problema. Uma delas envolve o uso de computação, seja via interface serial [1] ou através de micro controladores $(\mu \mathrm{C})$ do tipo PIC [2]. Um segundo tipo de solução envolve a construção de contadores eletrônicos [3] para determinar o tempo entre eventos. Recentemente, um terceiro tipo de sistema de detecção de movimento vem sendo também utilizado: a fotografia estroboscópica com o uso de câmeras fotográficas digitais, onde a base de tempo é o número de fotogramas que a câmera pode obter por segundo [4]. Embora esse método não seja tão preciso como os outros $(\Delta t=1 / 30 \mathrm{~s})$ ele não envolve as complexidades da eletrônica, que é um fator limitante sério na aplicação generalizada dos processos anteriores. Nesse processo, a posição espacial do objeto é obtida contra escalas colocadas no cenário, como referência. Todos esses métodos funcionam e seu uso depende da motivação e do conhecimento técnico daqueles que pretendem utilizar qualquer um deles. Os trabalhos que têm sido publicados com o uso de contadores digitais de tempo, no entanto, são de aplicabilidade limitada na área de ensino devido às complexidades das soluções propostas (montagens) em todos eles e, também, ao pouco conhecimento de eletrônica dos principais interessados que são os professores do ensino básico e/ou superior, principalmente os que militam fora dos grandes centros urbanos.

Os trabalhos que tem sido publicados nesse sentido consistem, essencialmente, de três partes: a) o disparo eletrônico do cronômetro; b) um sistema lógico que determina quando o cronômetro deve ser parado (e/ou registrar tempos intermediários) e c) um contador digital de tempo (o cronômetro, propriamente dito). Na parte (a), o acionamento eletrônico é feito geralmente por uma variação de uma corrente elétrica controlada por um dispositivo eletrônico que é detectada por um sensor o qual, por sua vez, gera um pulso de tensão que é aplicado ao circuito controlador do cronômetro, permitindo o início da contagem do tempo. A forma mais simples e a mais utilizada é a chave óptica (photogate) que consiste de um LED de luz infravermelha que ilumina um fototransistor polarizado para operar na região de saturação, ou modo digital, conduzindo a corrente máxima permitida: quando a borda do objeto em estudo corta o feixe luminoso, a corrente no fototransistor é também cortada provocando, então, uma comutação na tensão de controle. Essa variação de tensão dura enquanto o objeto estiver cortando o feixe luminoso. Esse sinal do fototransistor é, então, injetado no circuito de controle (parte b).

O sistema lógico (b) consiste de um circuito eletrônico que controla a maneira como os intervalos de tempo serão contados, ou seja, quando e como o cronômetro será parado. É nessa parte específica do projeto que está embutida toda a lógica e arte do trabalho. Quando uma única chave óptica for utilizada e se o corte seguinte do feixe luminoso parar o cronômetro, essa parte pode ser dispensada, como será mostrado mais adiante. Se os intervalos de tempo forem registrados entre diferentes pontos do espaço, serão necessárias diversas chaves ópticas (conforme o projeto experimental) e isso implicará, necessariamente, um circuito lógico intermediário adequado para definir quando e como os tempos intermediários serão registrados (esse assunto não será discutido no presente trabalho).

Nos trabalhos que têm sido propostos para o item (c) em geral, o cronômetro é formado por um oscilador com período de $0,01 \mathrm{~s}$, pelo menos quatro conjuntos formados, cada um, por um contador decimal (BCD), um decodificador, um acionador (driver) de mostradores de 7 segmentos e o mostrador digital. Essa parte, embora simples, é a mais difícil de ser implementada devido à quantidade de componentes, conexões e soldas, e à montagem. Acresce-se a isso o pouco conhecimento de eletrônica do pessoal potencialmente interessado e, também, a dificuldade desses componentes serem encontrados com facilidade fora dos grandes centros.

A alternativa proposta nesse trabalho é bastante simples e pode ser implementada em qualquer laboratório de ensino e é também de custo extremamente baixo, e consiste no uso de um cronômetro digital manual modificado para ser acionado e parado eletronicamente. A ideia central consiste na substituição do acionamento manual das funções do cronômetro digital por pulsos eletrônicos oriundos de uma chave óptica e injetados diretamente dentro dele. 
O presente trabalho é uma adaptação e generalização das ideias de A. Woothon [5], Galeriu [6] e Luiz [7] e é de implementação trivial, e é um produto que se destina, principalmente, a disponibilizar um material de alta precisão e de custo muito baixo a professores que militam no Ensino Médio e primeiros semestres de cursos universitários de ciência e tecnologia.

\section{Ligações do sistema}

Como foi dito na introdução, o sistema de medida de tempos é composto de três partes: (a) a chave óptica, (b) o sistema de controle, e (c) o cronômetro. A seguir passaremos a discutir em detalhes o funcionamento de cada uma dessas partes.

\subsection{A chave óptica}

Chave óptica é o nome genérico dado ao dispositivo óptico utilizado para registrar a passagem de um corpo por um dado ponto do espaço. Nos experimentos nos quais utilizamos chaves ópticas para detectar movimentos, a situação inicial do circuito é com o fototransistor iluminado, operando no modo saturado. Nesse caso, o fototransistor funciona como se fosse uma "chave fechada" (curto circuito entre o coletor e o emissor). No movimento do objeto em estudo, cada vez que ele passa pelo fototransistor a iluminação é cortada (como se essa chave se abrisse), gerando uma tensão $V_{0}$ na saída do circuito, que é utilizada para acionar o cronômetro.

A Fig. 1 mostra os diagramas eletrônicos habituais usados para chaves ópticas adotados no acionamento eletrônico de cronômetros. Esses circuitos são de uso geral e podem ser facilmente encontrados na internet (juntamente com dezenas de outras aplicações) utilizando-se nos "sites" de busca a entrada photogate circuits. Na Fig. 1a, quando o FT está iluminado, a tensão em seu coletor é aproximadamente zero. Assim, o transistor Q1 entra no corte e a tensão $V_{0}$ será $0 \mathrm{~V}$. Quando a iluminação é cortada, a tensão no coletor do FT sobe e coloca uma tensão $V_{C C}$ na base de Q1, levando-o à saturação. A tensão no emissor de Q1 vai a $V_{C C}$, e $V_{O}$ tem a mesma polaridade que o sinal na sua base. Nesse caso, o transistor de saída funciona como seguidor de emissor. Na Fig. 1b, quando o FT está iluminado a tensão no seu emissor é $V_{C C}$ e $V_{O}$ é próximo a $0 \mathrm{~V}$. Quando a iluminação é cortada, a tensão na base de Q1 vai a zero e Q1 entra no corte e a tensão no
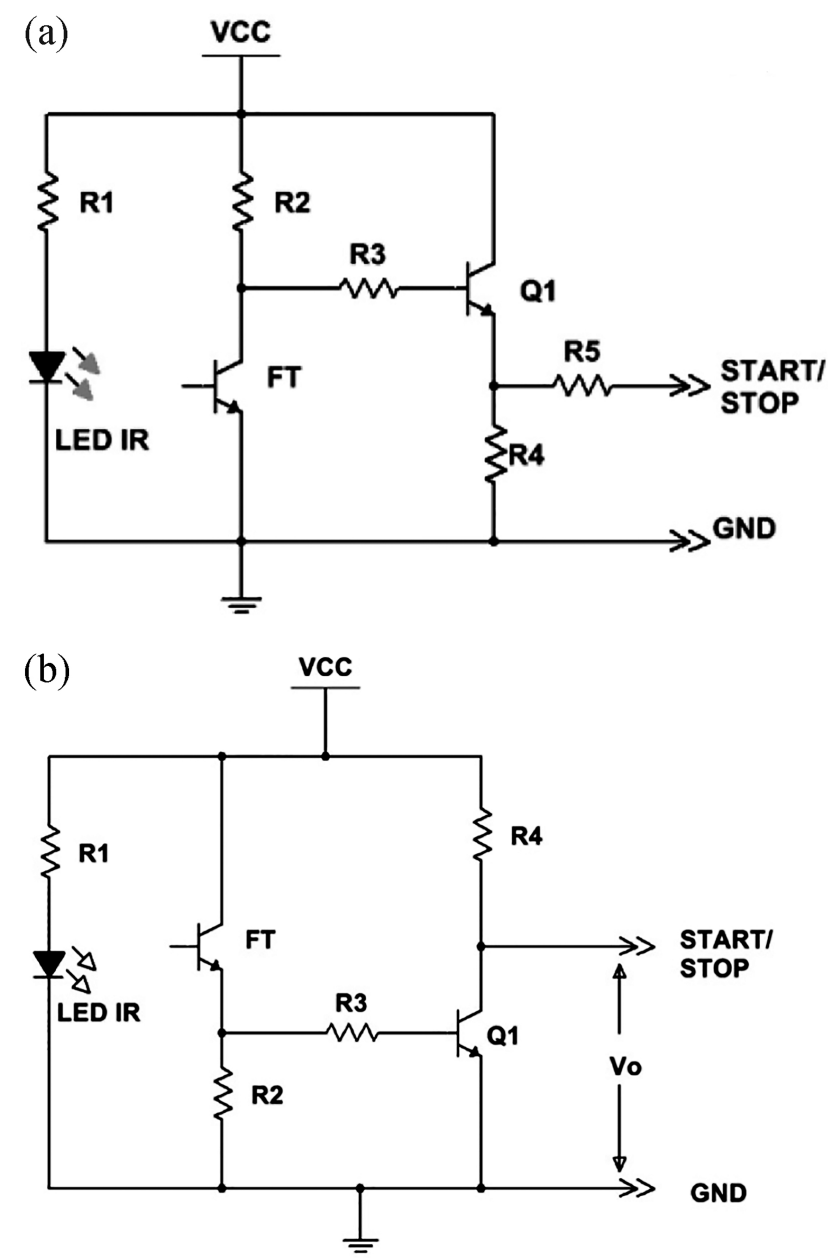

Figura 1: Diagramas habituais usados para chaves ópticas. Na Fig.1 (a), quando o FT está iluminado, a tensão em seu coletor é zero. Quando a iluminação é cortada, essa tensão sobe e coloca Q1 na saturação. A tensão no emissor de Q1 vai a $\mathrm{V}_{C C}$, e $\mathrm{V}_{O}$ tem a mesma polaridade. Nesse caso, o transistor de saída funciona como seguidor de emissor. $\mathrm{Na}$ Fig. 1 (b), quando o FT está iluminado a tensão no seu emissor é $V_{C C}$ e $V_{O}$ é próximo a $0 \mathrm{~V}$. Quando a iluminação é cortada, essa tensão vai a $V_{C C}$. Nesse caso, o transistor de saída funciona como circuito lógico inversor. Nesse trabalho estamos considerando que o cronômetro é acionado na transição positiva de $V_{O}$, ou seja, diagrama (b).

seu coletor vai a $V_{C C}$. Nesse caso, o transistor Q1 funciona como circuito lógico inversor.

Quaisquer das duas montagens da Fig. 1 funciona igualmente bem e seu uso é uma questão de conveniência e/ou preferência individual. Nessas figuras, o circuito da chave óptica é formado pelo sistema LED IR - FT, como descrito mais acima. O requisito básico para o fototransistor operar no modo digital é a resistência R2 ser maior que $5 \mathrm{k} \Omega$ [8]. A função do transistor Q1 é dupla: isolar o fototransistor do restante do circuito e, ao mesmo tempo, 
fornecer a polaridade correta para o acionamento do cronômetro. Em ambos os casos, transistor Q1 é polarizado para operar também no modo digital (ou comutação) [9].

No presente trabalho optamos pela montagem da Fig. 1b, com Q1 operando no modo emissor-comum, como será explicado mais adiante, pois necessitamos de um sinal positivo para acionar o cronômetro.

Na Fig. 2 indicamos o esquema eletrônico que adotamos para a chave óptica, com os valores dos componentes otimizados. Para que o circuito opere no modo comutação o valor do resistor R3 deve ser alto de forma a garantir a operação do transistor Q1 no modo digital (comutação), enquanto que R2 deverá ser, como vimos [8], maior que $5 \mathrm{k} \Omega$. Estamos utilizando um valor de $10 \mathrm{k} \Omega$. Finalmente, escolhemos um valor de $100 \Omega$ para R1 para permitir uma boa emissão de luz infravermelha pelo LED IR. A função de R5 é acrescentar uma proteção adicional ao transistor Q1. Os valores de R1, R4 e R5 foram calculados para uma tensão de alimentação de $5 \mathrm{~V}$, obtida de carregadores de telefones celulares GSM. Caso a tensão de alimentação seja muito alterada, esses valores devem ser reavaliados. Eles não são críticos.

\subsubsection{Ligações da chave óptica}

Existem inúmeras formas de se montar a chave óptica. A mais simples (e de mais baixo custo) consiste na montagem dentro de tubos e conexões de PVC soldável para água fria. No caso presente, utilizamos um tubo de $20 \mathrm{~mm}$ de diâmetro externo. A

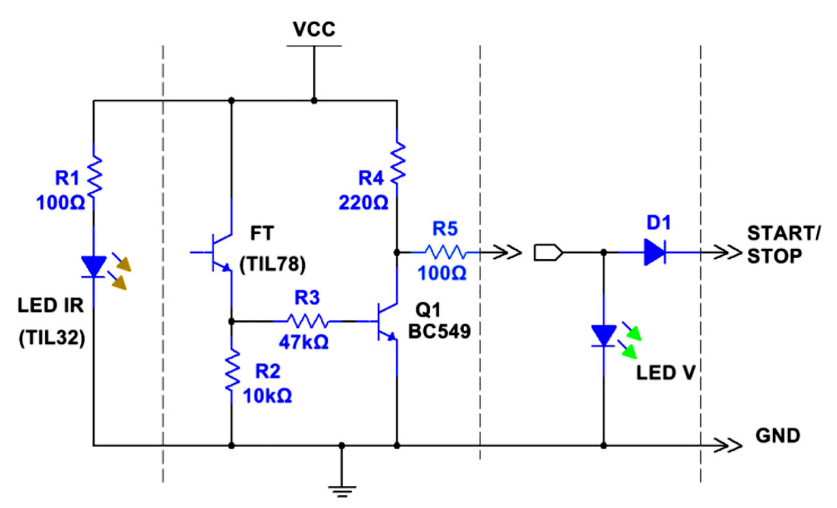

Figura 2: Esquema do circuito eletrônico otimizado da chave óptica. As linhas tracejadas separam as partes de iluminação, de detecção e de controle do cronômetro. O circuito pressupõe que o cronômetro é acionado por sinais positivos.
Fig. 3b mostra a fotografia da chave óptica montada. O lado esquerdo da figura corresponde ao circuito de iluminação e o lado direito ao de detecção. Para aproveitar o espaço disponível, monta-se o circuito de iluminação (circuito à esquerda da linha tracejada da Fig. 2) em um circuito impresso mostrado na Fig. 3a, colocado dentro do tubo lateral esquerdo da chave óptica. $\mathrm{O}$ circuito de detecção (circuito à direita da linha tracejada da Fig. 2) foi montado de acordo com o circuito impresso mostrado na Fig. 3c e colocado dentro do tubo vertical à direita da chave óptica.

Tanto o LED IR (TIL32) como o fototransistor (TIL78) são montados nas plaquetas de circuito impresso (Figs. 3a e 3c) via fios flexíveis finos, de comprimento conveniente, e encaixados em tarugos de PVC ou outro material opaco de cerca de $3 \mathrm{~cm}$ de comprimento e diâmetro igual ao diâmetro interno das conexões como sugerido na parte superior da Fig. 3b. Fazemos um furo de $3 \mathrm{~mm}$ nesses tarugos para colimar o feixe luminoso. Como o TIL32 utilizado possui $5 \mathrm{~mm}$ de diâmetro, foi necessário alargar um pouco o diâmetro do furo para poder encaixá-lo. O mesmo procedimento deve ser feito para o cabo de conexão na parte inferior da figura.

Como se pode verificar, a chave óptica trabalha com três sinais: a tensão de alimentação $V_{C C}$, a conexão de terra e o sinal de saída. Para conectar a chave óptica ao restante do sistema, utilizamos um

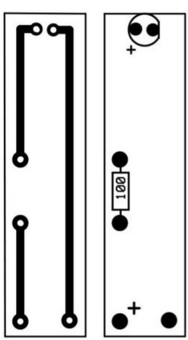

(a)

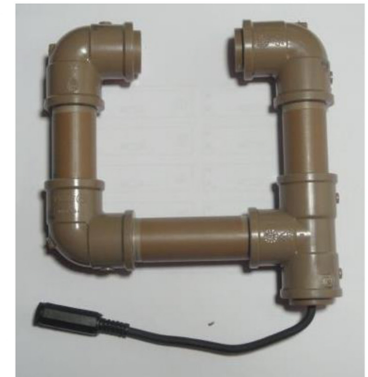

(b)

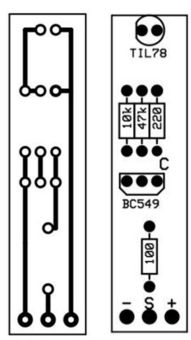

(c)
Figura 3: A Fig. 3a mostra o desenho do circuito impresso do foto emissor (lado esquerdo da Fig. 2); a Fig. 3b é uma fotografia da chave óptica montada onde aparece também o rabicho do cabo P2S fêmea, e a Fig. 3c é o equivalente da Fig. 3a para o circuito fotodetector. Nas figuras (a) e (c), as dimensões das plaquetas são $500 \times 2000 \mathrm{mil}(1 \mathrm{mil}$ corresponde a um milésimo de polegada). Na chave óptica, a distância utilizada entre os centros dos tubos verticais foi em torno de $10 \mathrm{~cm}$. Os desenhos dos circuitos impressos podem ser facilmente amplificados para as dimensões desejadas utilizando-se um editor de texto tipo Microsoft Word. 
cabo P2S estéreo de extensão, do tipo do cabo de som utilizado em microcomputadores. Esse cabo já vem com três fios: terra, ouvido esquerdo e ouvido direito. Devemos cortá-lo próximo do conector fêmea. Essa parte é soldada à chave óptica (Fig. 3b). A outra parte vai soldada a uma placa controladora do sistema, que é mostrada esquematicamente na Fig. 4. É conveniente manter a conexão de terra como no cabo original. As duas outras conexões devem ser ligadas uma à tensão $V_{C C}$ e a outra ao sinal de saída, o qual será injetado no cronômetro.

\subsection{A placa controladora}

O que chamamos de placa controladora é um circuito que faz a intermediação entre a chave óptica e o cronômetro, ou seja, a interface. Como foi dito na introdução, esse deve conter um circuito lógico que dá partida no cronômetro, determina as ações intermediárias e, também, o momento em que ele é parado. Como no sistema apresentado nesse trabalho determinamos apenas dois pontos: a partida e a parada, esse circuito lógico se faz desnecessário. A placa controladora tem como função a distribuição dos sinais: a fonte de alimentação do sistema, a entrada do sinal da chave óptica e a ligação física com o cronômetro.

Como os cronômetros digitais, em geral, são acionados por baterias de $\mathrm{Li}$ de $1,5 \mathrm{~V}$, é necessário casar a tensão de saída de Q1 $(\approx 5 \mathrm{~V})$ da chave óptica com a de entrada do cronômetro. Para fazer isso, ligamos o coletor de Q1, através de um resistor, a dois diodos: um LED verde (LED V) (amarelo ou laranja também servem) ligado à terra e um diodo de comutação comum (D1) que vai ligado ao botão START/STOP do cronômetro. A função do LED verde é funcionar como fonte regulada para a entrada do cronômetro. Como vimos, quando Q1 entra no corte, uma tensão $V_{C C}$ será aplicada no circuito do diodo. A tensão de barreira de um LED verde é em torno de 2,2 V. Portanto, circulará no diodo uma corrente dada aproximadamente por $I_{D}=\left(V_{C C}-2,2\right) / R(R=R 4+R 5+270)$. O valor $R=590 \Omega$ foi utilizado para manter uma corrente de coletor em torno de $8 \mathrm{~mA}$, suficiente para ativar o LED. Essa tensão de barreira $(2,2 \mathrm{~V})$ é então injetada no cronômetro via diodo D1, que provoca uma queda adicional de tensão da ordem de 0,7 V. A tensão do sinal injetada no cronômetro será, pois, em torno de 1,5 V, que é a tensão das baterias de Li que alimentam os cronômetros digitais Esse
LED verde poderia ser perfeitamente substituído por um diodo zener de $2,2 \mathrm{~V}$. A vantagem do uso de LED é o fato de ele servir também como ponto de teste (ou sinalizador) do circuito.

No circuito da Fig. 4 foram ainda implementados uma chave de contato momentâneo (pushbutton), normalmente aberta (PB-NO), com a finalidade de acionar manualmente a entrada reset do cronômetro, e a possibilidade da fonte de ali-
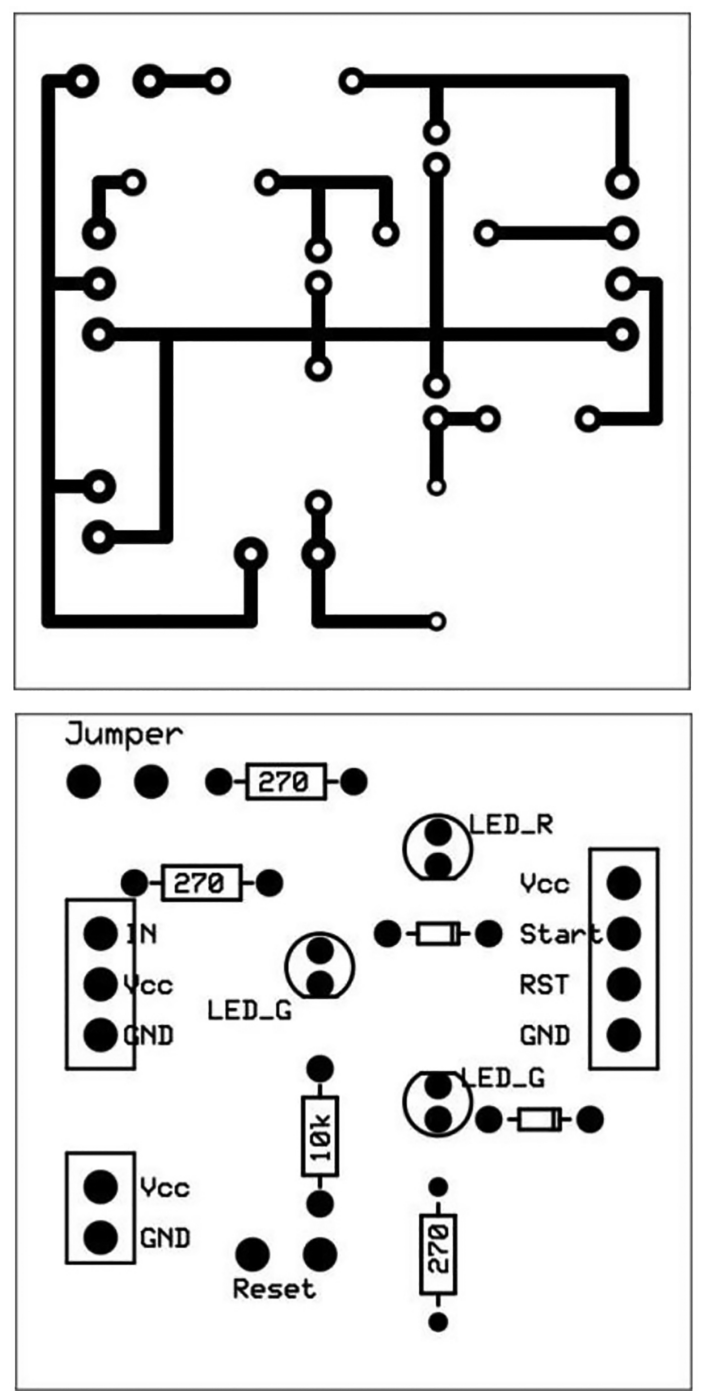

Figura 4: Desenho da placa controladora (ou centralizadora) do circuito mostrando os dois lados da placa. Na parte superior esquerda estão as conexões da chave óptica e na parte esquerda inferior as conexões da fonte de alimentação. À direita estão as conexões do cronômetro. A figura da esquerda corresponde ao lado das soldas do circuito impresso e o lado esquerdo ao lado dos componentes (silkscreen). Essas figuras são delimitadas por um quadrado com 2000 mil de lado. O jumper somente deve ser ligado na ausência de bateria no cronômetro. 
mentação da chave óptica alternativamente fornecer a tensão de operação ao cronômetro em caso de necessidade. No caso do reset, uma tensão $0 \mathrm{~V}$ é aplicada ao cronômetro via um resistor de $10 \mathrm{k} \Omega$ $+270 \Omega$. Quando a chave for pressionada, a tensão $V_{C C}$ aparecerá na junção desses resistores e, pelo procedimento descrito acima, uma tensão de $\approx 1,5 \mathrm{~V}$ é aplicada na entrada reset do cronômetro. Foi incluído também a possibilidade fornecer a tensão de alimentação ao cronômetro no caso da ausência de bateria. O princípio é o mesmo: intercala-se um resistor adequado entre a fonte de alimentação do circuito e um LED vermelho cuja tensão de barreira é $\approx 1,5 \mathrm{~V}$. Para tanto, liga-se um jumper no local indicado na Fig. 4.

\section{O cronômetro comercial 1}

Os cronômetros manuais digitais utilizam, essencialmente, dois botões. Um deles corresponde às funções start/stop (anda/para) e o outro à função reset, que tem dupla função: i) mostra tempos parciais enquanto o cronômetro não é parado, e ii) zera a leitura do cronômetro quando o cronômetro está parado. O seu funcionamento, portanto, na determinação de intervalos de tempo ocorre, em geral, através da sequência lógica

$$
\text { Start - Stop - Reset }
$$

A operação de qualquer uma dessas funções corresponde ao acionamento de uma chave mecânica, em geral uma lâmina metálica, que ao ser pressionada aplica uma tensão $V_{C C}$ no circuito do cronômetro, na forma indicada esquematicamente na Fig. 5, que mostra também os repiques aleatórios normalmente produzidos pelas chaves mecânicas (bouncing) [9], que é o fato de durante alguns poucos milissegundos antes da chave se estabilizar na posição final ela liga e desliga inúmeras vezes. Para evitar esse problema todos cronômetros possuem na entrada de seu circuito lógico um dispositivo que detecta a primeira transição positiva da chave, dando partida no contador de tempos, e desabilitando essa entrada enquanto o botão estiver sendo pressionado. Quando a placa controladora contiver um circuito de controle, um dispositivo antirrepique deverá ser introduzido na entrada de modo a evitar repetidos

\footnotetext{
${ }^{1}$ Nos dias de hoje, um cronômetro digital manual com $10 \mathrm{~ms}$ de resolução pode ser encontrado no mercado por cerca de $\mathrm{R} \$ 10,00$.
}
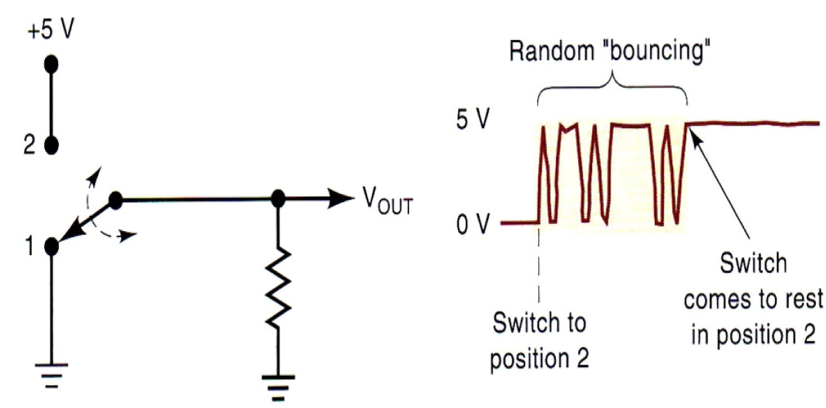

Figura 5: Quando um botão é pressionado (chave indo de 1 para 2), a tensão da bateria ( $5 \mathrm{~V}$, por exemplo) é aplicada ao cronômetro. Na figura, o contato mecânico repicará diversas vezes, produzindo múltiplas transições. A ocorrência dos repiques dura alguns milissegundos antes de se estabilizar [10].

acionamentos dessa, nos moldes dos circuitos apresentados nas Refs [2,3], e referências aí citadas, pois os componentes eletrônicos são muito rápidos e respondem a todos os repiques.

\subsection{Cronômetro}

Na conexão do cronômetro com o sistema eletrônico foi utilizado um cabo USB2 do tipo extensão (cabo macho/fêmea), onde cortamos a extremidade próxima ao conector tipo fêmea, com cerca de $10 \mathrm{~cm}$ de extensão e a soldamos à placa controladora do circuito (Fig. 4). A outra extremidade (livre) é soldada ao cronômetro conforme mostrado na Fig. 6 , onde introduzimos o cabo USB através de um furo na lateral do cronômetro no diâmetro do cabo. As soldas foram feitas da seguinte forma: a referência de tensão ou terra é soldada no circuito impresso do cronômetro em qualquer ponto de ligação com o negativo da bateria; a tensão de alimentação $V_{C C}$ é soldada em qualquer conexão ao lado positivo (carcaça) da bateria; o fio start/stop e o fio de reset são soldados no circuito impresso do cronômetro, respectivamente, nos locais do circuito impresso onde as molas dos botões correspondentes vão tocar quando acionados.

Deve ser tomado o cuidado para que as ligações no cronômetro correspondam àquelas indicadas na placa controladora. A Fig. 6 mostra essas conexões. Dessas ligações, a mais importante é a ligação de terra pois serve para referenciar todas as tensões do circuito da chave óptica. É uma ligação obrigatória! A conexão de terra deve ser a mesma para todas as partes do circuito. A razão de utilizarmos um cabo USB é em função da portabilidade do cronômetro, 


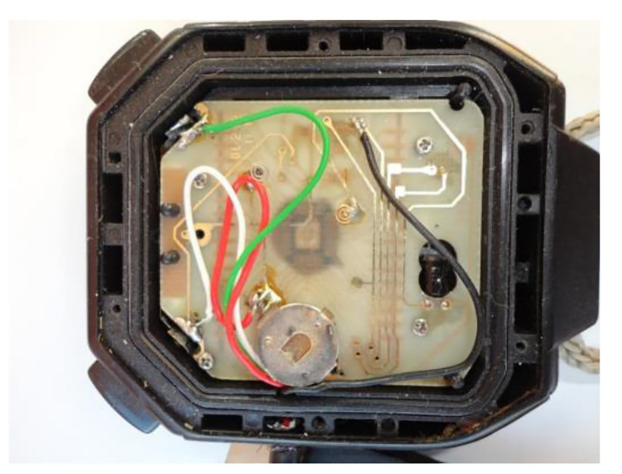

Figura 6: Esquema de ligações do cronômetro. A fiação do cabo (lado do conector macho) é soldada na placa do circuito impresso do cronômetro, na forma mostrada. Os fios devem ser soldados de acordo com as indicações na placa controladora.

que tanto poderá ser utilizado na forma descrita no presente trabalho como manualmente, desde que sua bateria esteja instalada e ativa (com carga!). Nesse caso, o pino da conexão da tensão de alimentação, na placa controladora (Fig. 4), não deve ser ligado. Para simplificar o projeto a zeragem do cronômetro (reset) poderá ser feita manualmente ou, alternativamente, podemos utilizar uma chave de contato momentâneo, tipo push-button para zerar o cronômetro, como mostrado na Fig. 4.

\subsection{Exemplo de aplicação}

A Fig. 7 mostra uma comparação entre duas tomadas de tempo do período de um pêndulo físico. Uma delas (círculos abertos) foi obtida por um observador experimentado, tomando todos os cuidados para obter o período com a maior acurácia possível (essa tarefa é facilitada pelas condições experimentais). A outra série (círculos cheios) foi obtida com o cronômetro e a chave óptica descritos no trabalho. Em ambas séries foram tomados tempos de apenas um período. Os resultados apresentados mostram a qualidade dos resultados obtidos via chave óptica. À guisa de informação, as medidas realizadas com a chave óptica foram realizadas, também, ao longo de três dias, fornecendo os mesmos resultados (como deveria ser!), mostrando a estabilidade do método.

\section{Conclusões}

Esse trabalho descreve um produto que pode ser facilmente implementado em qualquer laboratório de ensino onde se deseja determinar o movimento de

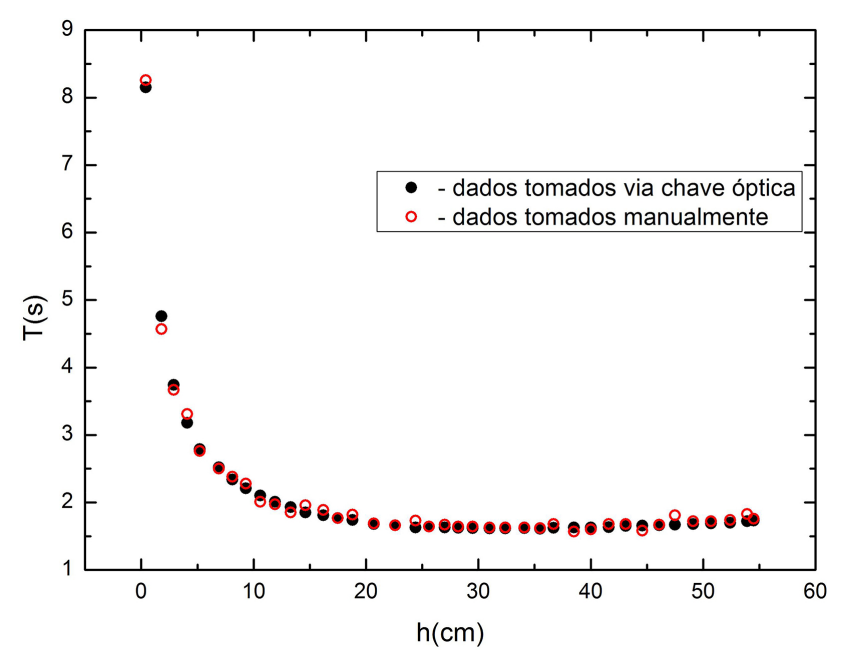

Figura 7: Gráfico do período de um pêndulo físico obtido via chave óptica (círculos cheios) e obtidos por uma pessoa treinada (círculos abertos).

um corpo em função do tempo. É de custo extremamente baixo, podendo ser montado por um técnico em eletrônica. No momento da submissão desse trabalho, a estimativa total de custo (fora mão de obra) foi de cerca de $\mathrm{R} \$ 50,00$. Seu objetivo básico é o de possibilitar ao pessoal docente, tanto dos semestres iniciais dos cursos tecnológicos como do Ensino Médio, condições de medir intervalos de tempo com o uso de cronômetros digitais. Ele buscou também dar esclarecimentos detalhados a respeito do funcionamento do sistema eletrônico com a finalidade de auxiliar as pessoas interessadas e com pouco conhecimento de eletrônica a desenvolver projetos análogos. No que diz respeito à confecção de circuitos impressos, nas figuras onde aparecem esquemas de circuitos impressos, foram dadas também as dimensões das placas para possibilitar sua reprodução. As figuras poderão ser escaneadas para um editor de texto tipo Microsoft Word e ajustadas para as dimensões informadas no texto. Para a confecção dos circuitos impressos, é recomendado a consulta via internet utilizando nos programas de busca as entradas "circuito impresso", "printed circuits", "PCB", etc. O método de confecção recomendado é o da impressão dos esquemas em papel fotográfico, papel vegetal ou transparências para fotocopiadoras, utilizando impressoras a laser com o contraste máximo. Os diversos passos nesse processo são encontrados com muita riqueza de detalhes na internet nos endereços obtidos nas buscas indicadas. 


\section{Referências}

[1] G. Dionisio e W.C. Magno, Revista Brasileira de Ensino de Física 29, 287 (2007).

[2] J.C. Andrades, A. Schiappacassa e P.F. Santos, Revista Brasileira de Ensino de Física, 35, 2503 (2013).

[3] R. Hessel, C.S. Oliveira, G.A. Santarine e D.R. Vollet, Revista Brasileira de Ensino de Física 30, 1501 (2008).

[4] M.A. Dias; Cad. Bras. Ens. Fis. 26, 492 (2009); E.P.M. Corveloni, E.S. Gomes, A.R. Sampaio, A.F. Mendes, V.L.L. Costa e R.C.Viscovini, Revista Brasileira de Ensino de Física 31, 3504 (2009).

[5] A. Wooton, Phys. Teach. 48, 405 (2000). Esse trabalho foi divulgado por A. Schiappacassa em suas notas de aula no CEFET (www.aridio.com.br), na aba "Física" (acessado em 11/11/2015).

[6] C. Galeriu, Phys. Teach. 51, 156 (2013).

[7] F.F. Luiz, L.E.S. Souza e P.H. Domingues, in: Anais do $5^{\circ}$ Encontro Nacional de Aprendizado Significativo, Belém, 2014, p. 790-795.

[8] Fairchild, Semiconductors, Application Note AN3005, disponível em ww. fairchildsemi.com

[9] R.L. Boylestad e L. Nashelsky, Dispositivos Eletrônicos e Teoria de Circuitos (Pearson, São Paulo, 2013), 11 ${ }^{\mathrm{a}}$ ed.

[10] R.J. Tocci, N.S. Widmer e G.L. Moss, Digital Systems, Principles and Applications (Pearson, New York, 2011), 11 ${ }^{\mathrm{a}}$ ed. 